\title{
Change of Stereoacuity with Aging in Normal Eyes
}

\author{
Se-Youp Lee, MD, Nam-Kyun Koo, MD \\ Department of Ophthalmology, Keimyung University School of Medicine, Dongsan Medical Center, Daegu, Korea
}

\begin{abstract}
Purpose: Stereopsis in normal subjects aged between 7 and 76 years was compared to examine changes in stereopsis with age.

Methods: Eighty subjects with no ocular disease were divided into 8 groups by age. Near stereopsis was evaluated with the TNO, Titmus, and Randot tests; distance stereopsis with the Mentor B-VAT II video acuity tester.

Results: The results of all 4 tests showed decreased stereopsis with increasing age $(p<0.05)$. Compared to the stereoacuity of 7 to 10-year-old group, both the TNO and distance stereopsis test results were significantly decreased for the 6th, 7th, and 8th decade groups, while both the Titmus and Randot test results were significantly decreased for the 8 th decade group $(p<0.05)$.

Conclusions: Overall, both near and distance stereopsis decreased with increasing age. Thus, decreased stereopsis should be taken into account when performing the stereopsis test. Korean Journal of Ophthalmology 19(2):136-139, 2005
\end{abstract}

Key Words: Distance stereopsis, Randot test, Stereopsis, Titmus test

Stereopsis is the ability to perceive the depth of field based on the disparity of the images formed by the two eyes; in other words, the fusion of the separated images on the Panum's area in order to perceive stereopsis by the two eyes. In 1838 , Wheatstone ${ }^{1}$ invented the stereoscope and discovered that if the areas on the retina of two eyes separated horizontally were stimulated simultaneously, stereopsis could occur. It has been reported that stereopsis is absent at birth and begins to develop from 4 months of age. ${ }^{2,3}$ Until now, there have been few reports on the change of stereopsis according to age. However, according to Romano et $\mathrm{al}^{4}{ }^{4}$ when stereopsis of children between the age of 18 months to 13 years was measured by Titmus test, stereopsis was improved with increasing age, and that from about 9 years old their stereopsis became equivalent to that of adults. $\mathrm{Jani}^{5}$ reported that in a study using the Flashlight diastereo test, stereopsis is improved from the age of 9 years up to 20 years, but deteriorates after the age of 40 years. Whilst there have been many reports in Korea on the stereopsis of children with abnormal binocular vision as well as normal children, ${ }^{6-9}$ there are few reports on the stereopsis of adults and the elderly. ${ }^{10}$

\footnotetext{
Received: January 12, 2005 Accepted: April 12, 2005

Reprint requests to Se-Youp Lee, MD. Department of Ophthalmology, School of Medicine, Dongsan Medical Center Keimyung University, \#194 Dongsan-dong, Jung-gu, Daegu 700-712, Korea. Tel: 82-53250-7720, Fax: 82-53-250-7705, E-mail: 1sy3379@dsmc.or.kr

* This study was presented in part at the Korean Ophthalmological Society Annual Meeting, 2004, Seoul, Korea.
}

Hence, we measured the distance and near stereopsis of normal children and adults with corrected visual acuity higher than 0.7 and examined the change of stereopsis according to age. We compared the stereopsis of other age groups with that of children under 11 years old when stereopsis is completed.

\section{Materials and Methods}

This study was performed on 80 normal individuals aged between 7 and 76 years old without eye diseases except refractive error. There were 40 males $(50 \%)$ and 40 females $(50 \%)$, with an average age of 36.9 years. Subject with corrected or uncorrected near visual acuity higher than 20/30 on near vision test chart (Northwestern University Medical school, Chicago, U.S.A.) and distance visual acuity higher than 0.7 by Dr. Hahn's standard test chart were included. Subjects with strabismus, amblyopia, anisometropia, glaucoma, or cataract, or with a history of eye surgery were excluded from the study population.

The subjects were separated into 8 groups of 10 cases each, with 5 males and 5 females per group. Group 1 comprised subjects from 7 to 10 years, group 2 from 11 to 20 years, group 3 from 21 to 30 years, group 4 from 31 to 40 years, group 5 from 41 to 50 years, group 6 from 51 to 60 years, group 7 from 61 to 70 years, and group 8 from 71 to 80 years.

Near stereopsis was assessed by the Titmus circle (Titmus, Optical Co, Inc., Chicago, IL, U.S.A.), Randot circle (Stereo Optical Co., Inc., Chicago, IL, U.S.A), and TNO (Lameris 
Ootech, Groenekan, Netherlands) tests. Distance stereopsis was assessed by the B-VAT II BVS contour circle (BVC) of the Mentor B-VAT II video acuity tester (Mentor O\&O, Inc., Norwell, Mass, U.S.A.). Refractive error of subjects having presbyopia was corrected and then Titmus circle, Randot circle, and TNO tests were performed with the subject at $40 \mathrm{~cm}$ distance, wearing Polaroid spectacles or red-green goggles, and with the test books properly adjusted and the visual axis of the subject vertical. In the determination of stereopsis, if the result was not correct more than two times consecutively, the previous result was considered as the examinee's stereopsis.

Distance stereopsis was measured after the correction of refractive error. With the subject at $6 \mathrm{~m}$ distance and wearing liquid crystal shutter glasses, 240 seconds of arc was performed. If the result was correct, it was considered a pass, but if it was incorrect, the location of the circle with different direction was then shown more than 2 times consecutively. If the result was now correct, the test proceeded to the next step, and if this step was passed, the test proceeded to the next high stereopsis. If stereopsis was not recognized at a certain step, the previous step was performed again, and when it was correct more than 2 times consecutively, the resulting value was considered as the final result. If 240 seconds could not be perceived, the subject was excluded from the study population for statistical analysis. As additional tests, slit lamp examination, intraocular pressure measurement, alternate prism cover test, refraction, and fundus examination were performed.

Statistical analyses of the comparison of stereopsis according to age and the assessment of the significance of the comparison of the group younger than 11 years old with other groups were performed by linear regression analysis using SAS (ver. 8.02, SAS institute). The level of significance was set at $\mathrm{p}<0.05$.

\section{Results}

The average age of each group was 8.6 years in group 1, 16.7 in $2,25.6$ in $3,35.3$ in $4,44.2$ in $5,54.7$ in $6,64.5$ in 7 , and 73.7 in 8 .

Stereopsis, as assessed by the near stereopsis tests with the Titmus circle, Randot circle and TNO tests and the distance stereopsis test with the BVC test, was significantly decreased as the age increased $(\mathrm{p}=0.0074,0.0015,<0.0001,<0.0001$, for the four tests, respectively)(Figs. 1 4).

Among near stereopsis tests, the average stereopsis in the Titmus circle from group 1 to group 8 was 43 seconds (standard error: \pm 4.8$), 41( \pm 3), 40( \pm 4.7), 39( \pm 5.3), 39$ $( \pm 3.1), \quad 70 \quad( \pm 54.9), \quad 94 \quad( \pm 60.4), \quad$ and $222 \quad( \pm 306)$, respectively. All test subjects passed the Titmus test. Group 8 , of those in their $70 \mathrm{~s}$, exhibited a statistically significant reduction of stereopsis compared to group $1(\mathrm{p}=0.0023)$.

The average stereopsis measured by the Randot circle test from group 1 to group 8 was 25.5 seconds $( \pm 4.3), 29$ ( \pm
9.3), $30.5( \pm 13.8), 29( \pm 17.1), 37.5( \pm 20.7), 53.5( \pm 24.7)$, 57 ( \pm 34$)$, and $118.5( \pm 145.9)$, respectively (Fig. 2). All study subjects passed the Randot circle test. Group 8, of those in their 70s, exhibited a statistically significant decrease of stereopsis compared to group $1(\mathrm{p}=0.0008)$.

The average stereopsis assessed by the TNO test from group 1 to group 8 was 46.5 seconds $( \pm 17.9), 49( \pm 26.3)$, $54( \pm 12.6), 75( \pm 30.7), 90( \pm 63.2), 180( \pm 137.4), 248.5$ $( \pm 171.2)$, and $300 \quad( \pm 180)$, respectively (Fig. 3). All subjects from group 1 to group 5 passed the test. In groups 6, 7 and 8, 1, 2 and 3 subjects, respectively, could not pass the test, and thus were excluded from the statistical analysis. Groups 6, 7 and 8 exhibited a statistically significant difference compared to group 1 (all $\mathrm{p}<0.001$ ).

The average stereopsis obtained by the BVC test from

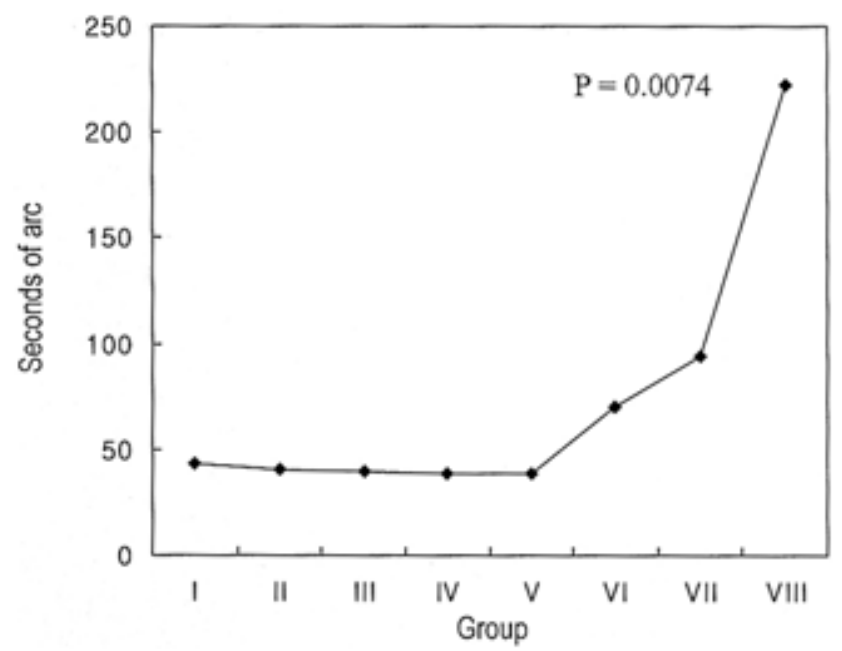

Fig. 1. Mean stereoacuity according to different age group by the Titmus test.

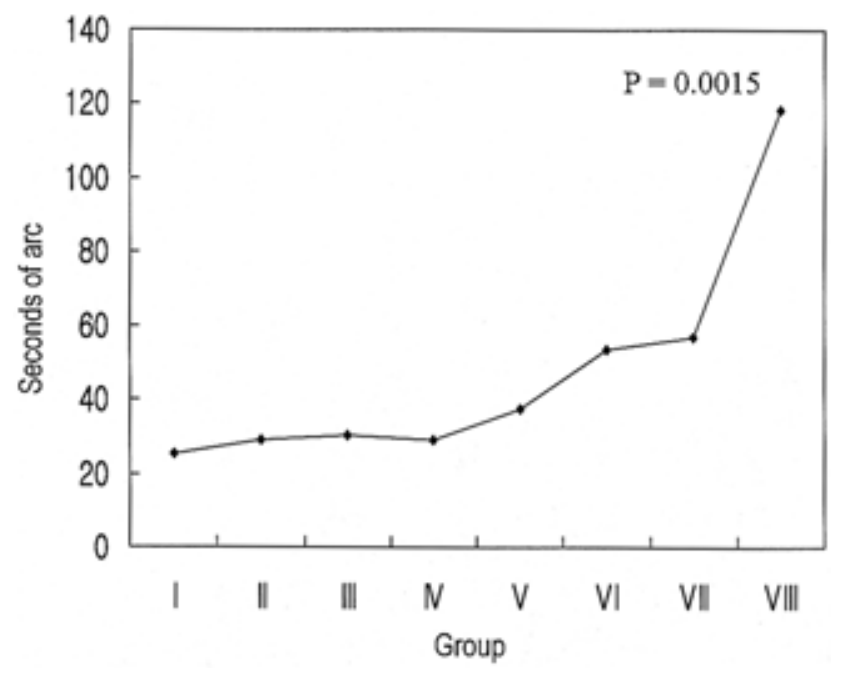

Fig. 2. Mean stereoacuity according to different age group by the Randot test. 


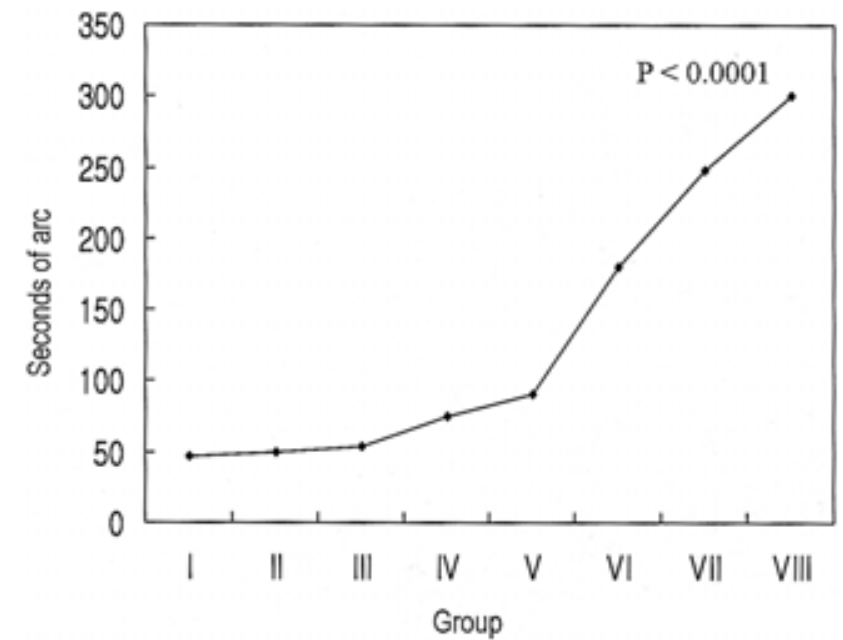

Fig. 3. Mean stereoacuity according to different age group by the TNO test.

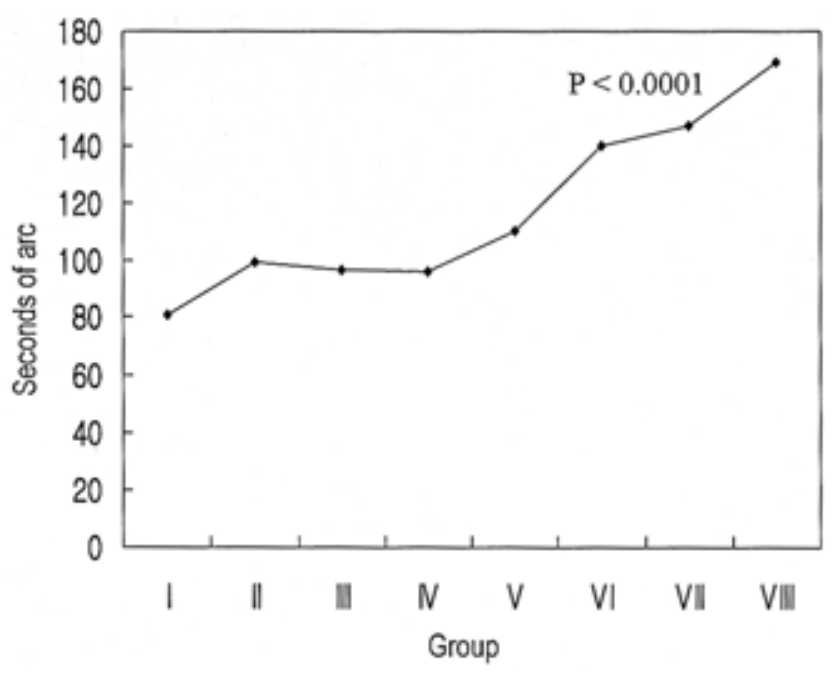

Fig. 4. Mean stereoacuity according to different age group by the Mentor B-VAT II video acuity tester.

group 1 to group 8 was 81 seconds $( \pm 58.3), 99( \pm 44.8)$, $96.6( \pm 46.9), 96( \pm 30.9), 110( \pm 42.4), 140( \pm 51.9), 147$ $( \pm 63.9)$, and $169.4( \pm 56.5)$, respectively, (Fig. 4). In groups 3,5 , and 6 , one subject in each group did not pass the test. Groups 6, 7 and 8 exhibited a statistically significant reduction compared to group $1(\mathrm{p}=0.0046,0.0023,0.0001$, respectively).

\section{Discussion}

Stereopsis is a pattern of the highest level of binocular vision, which refers to the ability to use the fovea of one eye and the macula of the other eye to perceive the depth of a subject in the fusion state of visualizing a subject, and thus to obtain binocular single vision. ${ }^{11,12}$ On the retina, the fovea has high spatial resolution power, and, therefore, even if the images formed by the two eyes are slightly different, a single image is perceived and thus detailed high stereopsis is possible. In the peripheral visual field, as its receiving unit is large, only a large disparity of the images can be perceived, and its stereopsis is thus decreased. Stereopsis is presented as the ability to perceive a very small seconds of arc of the depth between two points. In normal individuals, the standard of stereopsis test has been applied with the classification of shorter than 50 seconds as normal stereoscopic acuity and between $60-3,000$ seconds as partial stereoscopic acuity.

Various studies reported the change of stereopsis according to age. Tatsumi and Tahira ${ }^{13}$ reported that at the age of 7 years, stereopsis becomes equivalent to adults. Tiffin and Joseph $^{14}$ reported that the proportion passing the stereopsis test increased until the age of 40 years, but then subsequently decreased. Until now, the precise mechanism of the decrease of stereopsis according to age has not been elucidated; however, several reports showed that it was due to the association with the reduction of cerebral function. In regard to the decrease of stereopsis according to age, Cohn and Lasley $^{15}$ suggested a neural effect and reported the association of the loss of stereopsis and the initiation of dementia in dementia patients. Kiyosawa et $\mathrm{al}^{16}$ reported that among 8 Alzheimer patients, 5 reported a defect of visual function without a decrease of visual acuity. Wright and Wormald $^{17}$ reported a study on 728 cases of individuals over 65 years old without eye diseases, in which stereopsis was assessed by Frisby test. Stereopsis was good in only $27 \%$ and was absent in $29 \%$. They found the defect of stereopsis to be a common result, and reported that stereopsis decreases with increasing age. Sadun and Bassi ${ }^{18}$ reported that the loss of stereopsis may be due to the selective loss of retinal ganglion cells and Müller cells, rather than due to a defect in cerebral function.

In our study, near and distance stereopsis decreased as the age increased in all 4 tests. Particularly, in the groups older than 50 years, a reduction of stereopsis was evident. In the comparison with the group younger than 11 years when stereopsis is completed with other groups, stereopsis was clearly reduced in the $50 \mathrm{~s}, 60 \mathrm{~s}$ and 70 s by TNO test, in the $70 \mathrm{~s}$ by Titmus, and in the $70 \mathrm{~s}$ by Randot, and distance stereopsis was clearly decreased in the $50 \mathrm{~s}, 60 \mathrm{~s}$ and $70 \mathrm{~s}$. Our study subjects had no cataract or other eye diseases, which supports the theory that the cause is the reduction of cerebral function with aging.

The factors pertinent to stereopsis are visual acuity, pupillary distance, etc. In addition, the reading distance is increased in the elderly due to presbyopia, and stereopsis may be decreased due to cataract. Numerous studies in other countries reported the change of stereopsis with age. However, reports by Allen, ${ }^{19}$ Bell et al, ${ }^{20}$ HaegerstomPortnoy et $\mathrm{al}^{21}$ and Rubin et $\mathrm{al}^{22}$ all featured the shortcoming that the visual acuity measured at the time of the assessment of stereopsis was not adjusted. In other words, stereopsis may be decreased in the elderly due to the decrease 
of visual acuity. However, in our study, the visual acuity of most subjects was adjusted at near distance and far distance, and the subjects with 20/30 by near vision test chart and over 0.7 by Dr. Hahn's standard test chart were included. These findings suggest that the reduction of stereopsis is not associated with the decrease of visual acuity. Zaroff et $\mathrm{al}^{23}$ applied random dot stereoacuity test and reported that while $88 \%$ of under- 60 -year-old subjects showed normal stereopsis, only $37 \%$ of those in their 60 s and $25 \%$ of those in their 70 s did. Hence, the rate of stereopsis defects increased with increasing age. Particularly, it has been reported that the sensitive change was detected in the uncrossed disparity model in males, but in the crossed disparity model in females. Their conclusion was that the reduction of stereopsis with age is caused by various neurological factors linked to the general deterioration of cerebral function.

Our study findings were limited by the small sample size. Future research with a larger number of subjects is therefore required, as is the application in parallel of a method able to assess the loss of cerebral function. Hence, the potential reduction of stereopsis with increasing age should be borne in mind when interpreting stereopsis measurements of subjects over 50 years old.

\section{References}

1) Wheatstone C. Contributions to the physiology of vision. Part the first. On some remarkable and hitherto unobserved phenomena of binocular vision. Philos. Trans $R$ Soc Lond $B$ Biol Sci 1838;371:128.

2) Birch B, Williams C, Hunter J, Lapa MC. Random dot stereoacuity of preschool children. I Pediatr Ophthalmol Strabismus 1997;34:217-22.

3) Tyler CW. Sensory processing of binocular disparity. In : Schor CM, Cuiffreda KJ, eds. Vergence Eye Movement: Basic and Clinical Aspects. Boston, Mass: Butterworths, 1983;199-295.

4) Romano PE, Romano JA, Puklin JE. Stereoacuity development in children with normal binocular single vision. Am J Ophthalmol 1975;79:966-71.

5) Jani SN. The age factor in stereopsis screening. Am J Optom 1966;43:653-7.
6) Lee BH, Kim MM. Comparison of the Lang, Randot, TNO and new stereotests in screening and office use in children. J Korean Ophthalmol Soc 1990;31:651-60.

7) Lee SY, Park WT. Assessment of stereoacuity with the Frisby and Lang II stereotests in preschool children. $J$ Korean Ophthalmol Soc 1998;39:2165-72.

8) Lee SY, Bae SH. Assessment of stereoacuity with the Randot preschool stereoacuity and Lang test in the 2- to 5-year age range. J Korean Ophthalmol Soc 1999;40:138590.

9) Lee SY, Bae SH. Comparison of various kinds of stereoacuity tests in preschool children. $J$ Korean Ophthalmol Soc 2000;41:1383-8.

10) Cho YA, Cho SW, Roh GH. Evaluation of criteria of stereoacuity for Titmus, Randot \& TNO stereotests. $J$ Korean Ophthalmol Soc 1999;40:532-7.

11) Tychsen L. Binocular vision. In : William MH, ed. Adler's physiology of the eye, 9th ed. St. Louis: Mosby, 1992; 773-853.

12) von Noorden GK. Binocular vision and ocular motility, 5th ed. St. Louis: Mosby, 1996;8-40.

13) Tatsumi S, Tahira K. Study on the stereotest (Titmus) in childhood. Folia Ophthalmol Jpn 1972;23:620-32.

14) Tiffin B, Joseph S. Industrial Psychology. New York: Prentice-Hall Inc, 1942;134-5.

15) Cohn TE, Lasley DJ. Visual depth illusion and falls in the eldly. Clin in Geriatric Med 1985;3:608-11.

16) Kiyosawa M, Bosley TM, Chawluk J, et al. Alzheimer's disease with prominent visual symptoms. Ophthalmology 1989;96:1077-86.

17) Wright LA, Wormald RPL. Stereopsis and ageing. Eye 1992;6:473-6.

18) Sadun AA, Bassi CJ. Optic nerve damage in Alzheimer's disease. Ophthalmology 1990;97:9-17.

19) Allen MJ. Vision screening at Indiana State Fair. $J \mathrm{Am}$ Optom Assoc 1964;35:974-7.

20) Bell B, Wolf E, Bernholz CD. Depth perception as a function of age. Aging Hum Dev 1972;3:77-81.

21) Haegerstom-Portnoy G, Schneck ME, Brabyn JA. Seeing into old age: vision function beyond acuity. Opted Vis Sci 1999;76:141-58.

22) Rubin GS, West SK, Munoz B, et al. A comprehensive assessment of visual impairment in a population of older Americans. Invest Ophthalmol Vis Sci 1997;38:557-68.

23) Zaroff CM, Knutelska M, Frumkes TE. Variation in stereoacuity: normative description, fixation disparity, and the roles of ageing and gender. Invest Ophthalmol Vis Sci 2003;44:891-900. 